\title{
Geometric modelling and materially nonlinear numerical analysis of shells in the shape of one-sheet hyperboloid of revolution
}

\author{
Mathieu Gil-oulbé1, Muhannad Jazzan², Jaafar Qbaily ${ }^{3}$ \\ Peoples' Friendship University of Russia (RUDN University), 6 Miklukho-Maklaya St., Moscow, 117198, Russian Federation
}

\section{Keywords:}

hyperboloids of revolution;

materially nonlinear numerical analysis;

finite elements linear analysis;

finite elements nonlinear analysis;

geometric modeling

\section{Article history:}

Received: March 12, 2019

Revised: May 14, 2019

Accepted: June 10, 2019

\section{For citation}

Gil-oulbé M., Jazzan M., Qbaily J. (2019). Geometric modelling and materially nonlinear numerical analysis of shells in the shape of onesheet hyperboloid of revolution. Structural Mechanics of Engineering Constructions and Buildings, 15(3), 210-218. http://dx.doi.org/10.22363/ 1815-5235-2019-15-3-210-218

\section{Abstract}

Aims of research. A surface of revolution is generated by rotation of a plane curve $z=f(x)$ about an axis $O z$ called the axis of rotation. This paper provides information on hyperboloids of revolution surfaces and their classification. Their geometric modeling, linear and materially nonlinear analysis are worked out.

Methods. Hyperboloids of revolution middle surface is plotted using the software MathCAD. The linear and materially nonlinear numerical analyses of thin shells of the shape of an hyperboloid of revolution surfaces on stress-strain state is given in this paper, using the finite elements method in a computer software $\mathrm{R}-\mathrm{FEM}$, the material which we use in our model is concrete with isotopic nonlinear 2D/3D stress-strain curve for materially nonlinear analysis and linear stress-strain curve for linear analyses. Comparison is done with the result of the finite elements linear analysis of their strain-stress results.

Results. That displacements in the investigated shells subject to self-weight, wind load with materially nonlinear analysis are bigger than which done by linear analysis, in the other side the displacements is similarity subjected to free vibration load case. Based on these results, conclusions are made for the whole paper.

\section{Introduction}

A surface of revolution is generated by rotation of a plane curve $z=f(x)$ about an axis $O z$ called the axis of rotation of that surface. The resulting surface therefore always has azimuthal symmetry. Hence, an explicit equation of a surface of revolution can be presented in the following form

$$
z=f(r)=f\left(\sqrt{x^{2}+y^{2}}\right),
$$

where $r=\sqrt{x^{2}+y^{2}}$ is the distance of a point of the surface from the axis of rotation.

Right cylindrical and conical surfaces are examples of surfaces generated by a straight line when the

${ }^{1}$ Mathieu Gil-oulbé, $\mathrm{PhD}$ in Technical Science, Associate Professor, Department of Civil Engineering, Engineering Academy, gil-oulbem@hotmail.com

${ }^{2}$ Muhannad Jazzan, Master's Degree Student, Department of Civil Engineering, Engineering Academy.

${ }^{3}$ Jaafar Qbaily, Master's Degree Student, Department of Civil Engineering, Engineering Academy.

(C) Gil-oulbé M., Jazzan M., Qbaily J., 2019

This work is licensed under a Creative Commons Attribution 4.0 International License line is coplanar with the axis, as well as hyperboloids of one sheet when the line is skew to the axis. A sphere is a surface of revolution of a circle around an axis that passes through the center of the circle. If the circle is rotated about a coplanar axis, not crossing the circumference, then it generates a torus.

Meridians are the lines of intersections of a surface of revolution with planes passing through an axis of rotation. All meridians of one surface of revolution are congruent to the rotated curve. A plane passing through the axis of the surface of revolution is called the meridian plane. It is the plane of symmetry of the surface. Any surface of revolution has the infinite number of planes of symmetry. Parallels are the lines of intersection of the surface with planes orthogonal to an axis of rotation. Meridians and parallels of a surface of revolution are the lines of principal curvatures. Any normal of surfaces of revolution intersects its axis of rotation. A surface of revolution having more than one axis of rotation is a sphere or a plane.

Tangents to all meridians in the points located on one parallel circle are lines on the tangent conical 
(or cylindrical) surface of revolution, which is created by the revolution of the tangent about the axis of the rotation. A vertex of the tangent conical surface is located on the axis of revolution. A parallel is called the neck circle, if tangent planes to the surface of revolution in the points on this circle are parallel to the axis of revolution and the tangent cylindrical surface is located inside the surface of revolution. A parallel is called the equator circle, if tangent planes to the surface of revolution in the points on this circle are parallel to the axis of revolution and the tangent cylindrical surface is located outside the surface of revolution. A parallel is called the crater circle, if tangent plane to the surface of revolution in the points on this circle is perpendicular to the axis of revolution and normal to the surface of revolution in the points of this parallel are parallel to the axis of revolution and form the normal cylindrical surface.

Umbilical points of a surface of revolution are placed on those latitudes on which a center of curvature of a meridian is located on the axis of rotation. Sphere is umbilical surface. Under Alexis-Claude Clairaut theorem, the product of a radius of a parallel into cosines of an angle of intersection of the geodesic line with the parallel is constant along the geodesic line.

A surface of revolution admits bending into another surface of revolution and a net of lines of principal curvatures is remained. Parametrical equations of arbitrary surface of revolution are

$$
r=r(r, \beta)=r \cdot \sin (\beta) \cdot i+r \cdot \cos (\beta) \cdot j+f(r) \cdot k .
$$

Assume an equation of a meridian in the form $r=r(\alpha)$ where $\alpha$ is the angle of the normal to the surface passing through a given point with the axis of rotation (Figure 1) then $r=R_{2} \sin (\alpha)$.

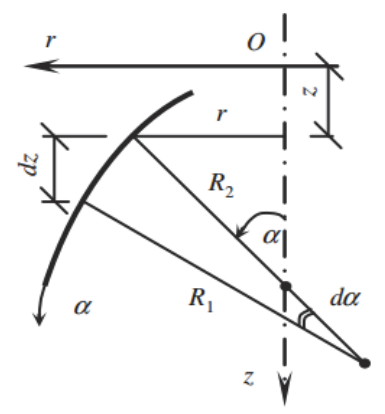

Figure 1. Kinematics of generating of a surface of revolution

Coefficients of the fundamental forms of the surface of revolution can be obtained with the help of formulas:

$$
\begin{aligned}
& A=A(\alpha)=R_{1}(\alpha), \\
& B=B(\alpha)=r=R_{2} \cdot \sin (\alpha),
\end{aligned}
$$

$$
F=0, L=R_{1}(\alpha), M=0, N=R_{2} \cdot \sin (\alpha),
$$

where $R_{l}$ is the principal radius of curvature of the meridian that is the coordinate line of $\alpha, R_{2}$ is the principal radius of curvature of the parallel.

The lines $\alpha=$ const are parallels and the lines $\beta=$ const are meridians. If an equation of a meridian is given in the form $r=r(z)$ (Figure 1) then an equation of a surface of revolution can be written with the help of three scalar equations:

$$
x=r \cdot \sin (\beta), y=r \cdot \cos (\beta), z=z,
$$

where $r=r(z)$ is a function that determines the shape of the meridian (a profile curve); $\beta$ is the angle of rotation of the plane of the meridian and then

$$
\begin{aligned}
& A=\sqrt{1+r^{\prime 2}}, F=0, B=r(z), \\
& k_{1}=\frac{1}{R_{1}}=-\frac{r^{\prime}}{\left(1+r^{\prime 2}\right)^{\frac{3}{2}}}, k_{2}=\frac{1}{R_{2}}=-\frac{1}{r \cdot \sqrt{1+r^{\prime 2}}},
\end{aligned}
$$

where the derivatives with respect to $z$ are denoted by primes; $k_{1}, k_{2}$ are principal curvatures of the surface.

Normal curvature of a surface in the direction of the meridian is equal to a curvature of the meridian, i.e., $k_{l}$. Meridians of surface of revolution are geodesic lines. Catenoid is the only one minimal surface of revolution. One-sheet hyperboloid of revolution, right circular cylinder and right circular cone are the only ruled surfaces. The last two surfaces are the only developable surface of revolution. If a beginning and an end of unclosed rotated line are placed on an axis of rotation, then the surface of revolution will be the closed one.

\section{Geometric Modeling}

One-sheet hyperboloid of revolution is generated by the rotation of hyperbola about the $z$-axis (Figure $2, a$ ). These are twice ruled surface.

$$
\frac{x^{2}}{a^{2}}-\frac{z^{2}}{c^{2}}=1 .
$$

Thorough every point of the surface, two straight lines, lying on the hyperboloid, pass (Figure 2, $b$ ). A hyperboloid can be constructed by rotation of a generatrix straight line about the $z$-axis but the straight generatrix and the axis are skew lines (Figure 2,c and $d$ ). The surface is the only one ruled surface of revolution of negative Gaussian curvature. The parallel lying in a plane $z=0$ has a radius $r=a$ and is called $a$ waist circumference that represents a geodesic line. All of the rest of the geodesic lines besides the equator go from infinity coming.

Nearer to the equator. One of them intersects the equator and goes to other half of the surface but others do not reach the equator and touching the some parallel, turn back; the third geodesic lines come nearer asymptotically to the equator. 

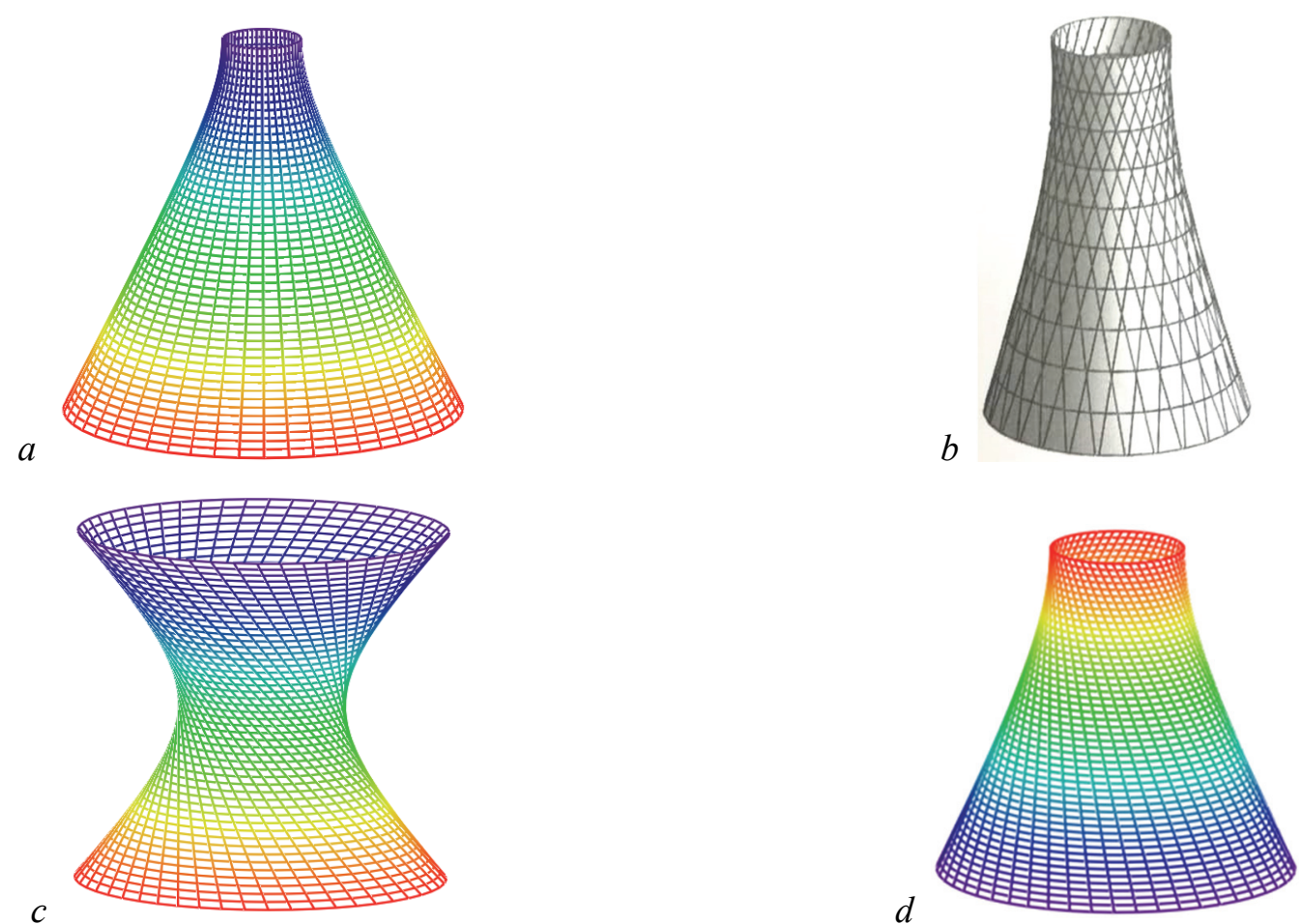

Figure 2. Varieties of hyperboloids of revolution

\section{Forms of definition of one-sheet hyperboloid of revolution}

1) Implicit equation (canonical equation):

$$
\frac{\left(x^{2}+y^{2}\right)}{a^{2}}-\frac{z^{2}}{c^{2}}=1 \text {. }
$$

If $a=c$, then a hyperboloid is called a right hyperboloid.

2) Parametrical equation (Figure 2, $c$ and $d$ ):

$$
\begin{aligned}
& x=x(u, v)=-a \cdot \sin (u) \mp a \cdot v \cdot \cos (u), \\
& y=y(u, v)=a \cdot \cos (u) \mp a \cdot v \cdot \sin (u), \\
& z=z(v)=\mp c \cdot v .
\end{aligned}
$$

Coefficients of the fundamental forms of the surface:

$$
\begin{gathered}
A^{2}=a^{2} \cdot\left(1+v^{2}\right), B^{2}=a^{2}+c^{2}, F=\mp a^{2}, \\
L=\frac{\mp c \cdot a^{2} \cdot\left(1+v^{2}\right)}{\left(A^{2} \cdot B^{2}-F^{2}\right)^{0.5}}, M=\frac{a^{2} \cdot c}{\left(A^{2} \cdot B^{2}-F^{2}\right)^{0.5}}, N=0 .
\end{gathered}
$$

Coordinate lines $v(u=$ const $)$ coincide with one system of straight lines but the lines $u$ are the parallels of the hyperboloid of one sheet. In Figure 2, $c$ the hyperboloid is shown, taking into consideration the upper signs in the parametrical equations (6) of the surface. The lower signs are taken into account in Figure 2, $d$.

3) Parametrical equations (Figure 2, $a$ ):

$$
x=x(r, \beta)=r \cdot \cos (\beta),
$$

$$
\begin{aligned}
& y=y(r, \beta)=r \cdot \sin (\beta), \\
& z=z(r, \beta)=\frac{c \cdot \sqrt{r^{2}-a^{2}}}{a} .
\end{aligned}
$$

Coordinate lines $r$ and $\beta$ (parallels and meridians) are the lines of principal curvatures.

4) Parametrical equations (Figure 2,a):

$$
\begin{aligned}
& x=x(r, z)=\frac{a}{c} \cdot \sqrt{c^{2}+z^{2}} \cdot \sin (\beta), \\
& y=y(r, z)=\frac{a}{c} \cdot \sqrt{c^{2}+z^{2}} \cdot \cos (\beta), \\
& z(r, z)=z .
\end{aligned}
$$

Coordinate lines $z$ and $\beta$ (parallels and meridians) are the lines of principal curvatures.

5) Parametrical equations (Figure 2, $a$ ):

$$
\begin{aligned}
& x=x(\alpha, \beta)=a \cdot \operatorname{ch}(\alpha) \cdot \cos (\beta), \\
& y=y(\alpha, \beta)=a \cdot \operatorname{ch}(\alpha) \cdot \sin (\beta), \\
& z=z(\alpha, \beta)=c \cdot \operatorname{sh}(\alpha) .
\end{aligned}
$$

Coefficients of the fundamental forms of the surface and its principal curvatures:

$$
\begin{aligned}
& A^{2}=a \cdot \operatorname{ch}(\alpha), B^{2}=a^{2} \cdot \operatorname{sh}^{2}(\alpha)+c^{2} \cdot c h^{2}(\alpha), \\
& F=0 \\
& L=-a \cdot c \cdot \frac{c h^{2}(\alpha)}{B}, K_{1}=-\frac{c}{a \cdot B}, K_{2}=\frac{a \cdot c}{B^{3}} .
\end{aligned}
$$




\section{Overview of literature}

The most complete work on the history of the development of hyperboloid structures in domestic construction is the monograph of I.A. Petropavlovskaya [1].

The article [2] gives a comparative analysis of the stability of the initial form of equilibrium of reticulated shells in the form of single-sheeted hyperboloids of revolution. The analyses are performed both considering only geometric and double (geometric and physical) nonlinearity. The influence of the shape of the generatrix of a single-sheeted hyperboloid of revolution and the physical nonlinearity of the material on its stability in the indicated formulations of the problem is considered. The curves of the equilibrium states of the shells under load acting on the upper base are given.

In the review article [3] are summarized principal achievements of science and engineering in the sphere of design, construction, and static, vibrational, and buckling analysis of thin-walled constructions and buildings in the shape of hyperbolic surfaces of revolution. These shells are useful as hyperbolic cooling towers, TV towers, reinforced concrete water tanks, and arch dams. They are also used as supports for electric power transmission lines and as high chimneys. Several public and industrial buildings having the hyperbolic form are described in the review. The basic results of theoretical and experimental investigations of stress-strain state, buckling, and vibration are summarized. The influence of temperature and moisture on the stress-strain state of the shells in question is also analyzed.

In book [4] J.N. Reddy presents the theory and computer implementations of the finite element method as applied to nonlinear problems of heat transfer and similar field problems, fluid mechanics (flows of incompressible fluids), and solid mechanics (elasticity, beams and plates). Both geometric as well as material nonlinearities are considered, and static and transient (i.e.: time-dependent) responses are studied.

S.I. Trushin and Ph.I. Petrenko in paper [5] investigated the influence of form of hyperboloid's generatrix on its stress-strain state, stability and fundamental frequency. The results of numerical analysis of reticulated shells under different loads are given.

The article [6] studies the impact of the shape of the generatrix of a discrete reticulated shell in the form of a one-sheet hyperboloid of revolution on its stability. It studies the stability of a reticulated hyperboloid with five types of frames formed from the generatrices of the hyperbolae with one asymptote. For comparison, the study examines an additional frame with rectilinear generatrices - the asymptotes of hyperbolae generatrices, the properties of which are dif- ferent from those of shells with a curvilinear rod network. The work presents the results of the numerical analysis of the reticulated shell performed with the help of finite element method in a geometrically non-linear setting. The article also presents the curves of the equilibrium states of the shell under horizontal and vertical concentrated loads. The data obtained has made it possible to conclude on the impact of the used generatrix on the stability of the frame of reticulated shells in the form of hyperboloid of revolution.

\section{Linear and materially nonlinear analyses (MNA) of thin shells in the shape of one-sheet hyperboloid of revolution}

In the linear material model, the stress-strain relationship must be linear with slope $E$, Young's Modulus (Hooke's law):

$$
\sigma=E \cdot \varepsilon,
$$

where $\sigma$ is the normal stress and $\varepsilon$ is the strain.

Material nonlinearity is a concern whenever the response at the operating loads causes strain levels in a material beyond the portion of the stress-strain curve that can reasonably be approximated as linear. Many materials have curves that deviate small amounts from linear for large amounts of strain so that, with all the other uncertainty in the model, there would be little value in a nonlinear material model. On the other hand, many curves deviate from linear almost immediately to such a degree that only the roughest trend studies can be made with a linear approximation.

The constant of proportionality in a linear material model is Young's Modulus. This represents the slope of the linear portion of the stress-strain curve (Figure 3). For highly nonlinear materials, this modulus may only be applicable at very low strains.

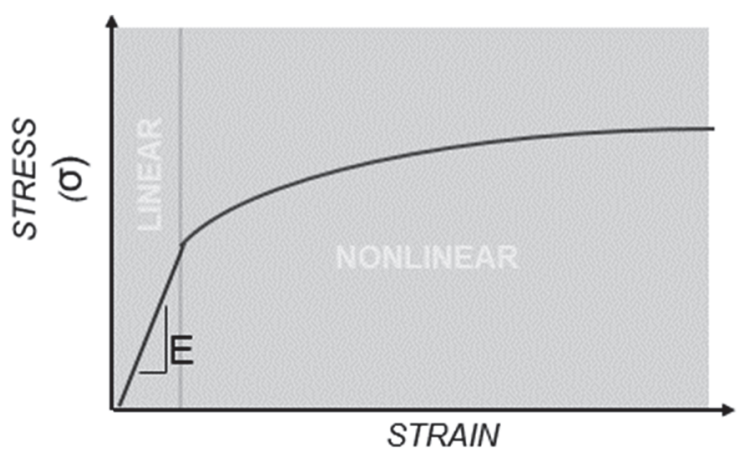

$(\varepsilon)$

Figure 3. Stress-strain curve

Nonlinear material models of common engineering materials are defined by specifying their stressstrain curves. Most stress-strain curves represent on- 
ly the tensile response. When a material has the same response in tension and compression, it is said to be symmetric. Cast iron is a good example of an asymmetric stress-strain behavior as it is stronger in compression than tension.

\section{Types of nonlinear materials}

There are several types of material nonlinearity that might be present in a structural analysis: $1-$ nonlinear elastic; 2 - bi-linear elastic-plastic; 3 - multilinear plastic; 4 - hyperplastic; 5 - viscoelastic.

Simplified models of stress-strain curves are shown in Figure 4.

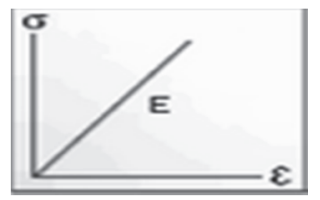

Linear elastic

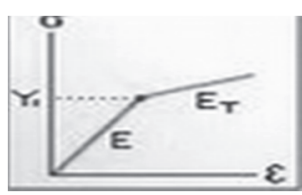

Bi-linear elasto-plastic

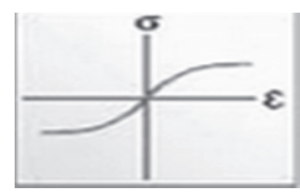

Nonlinear elastic

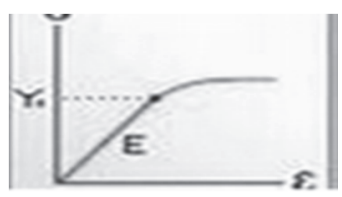

Multi-linear plastic
Figure 4. Types of nonlinear materials

A nonlinear material model can be defined as nonlinear elastic where the part returns to a zero strain state when the load is removed or elastic-plastic where permanent strain begins to accumulate after reaching the yield strength of the material.

Additionally, an elastic-plastic stress-strain curve can be input as bi-linear, where only an elastic modulus and a plasticity or hardening modulus are entered. It can also be defined as a multi-linear stress-stress curve where the true nonlinearity of the plastic range can be captured with a series of points.

\section{The comparison of the linear and materially nonlinear results MNA}

Let us consider concrete c20/25 as a material for our model. The shell are subject to the following loads: 1 - self-weight; 2 - wind load on $+Y$ direction. The shells are investigated with fixed supports. The load combinations in the used software RFEM is: (1.4. selfweight +1.6 -wind loads) according to Eurocode. The dimensions for our model are the following: height $36 \mathrm{~m}$, the upper diameter $20 \mathrm{~m}$, the diameter on base $31.5 \mathrm{~m}$, thickness $15 \mathrm{~cm}$.

For materially nonlinear analysis we use isotopic nonlinear 2D/3D concert as following (Figure 5).
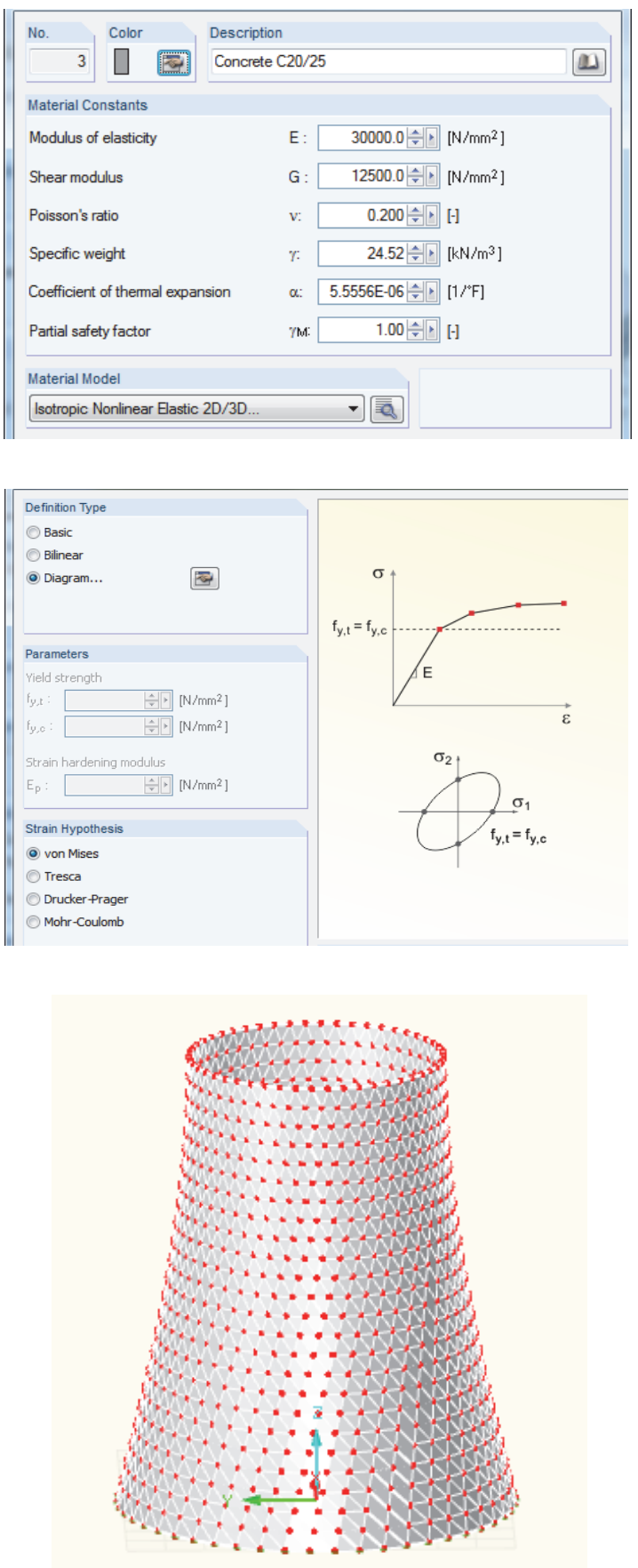

Figure 5. FE design model of thin shells in the shape of one-sheet hyperboloid of revolution in RFEM

The results of our investigation are showed the maximum displacements for our structure under loads at three direction with linear and nonlinear analysis (Figures 6 and 7).

Linear and materially nonlinear analyses are made for this structure under free vibration to show the influence of materially nonlinear analysis under free vibration.

Let us assume three vibration pattern for our analysis, the results are showed in table. 

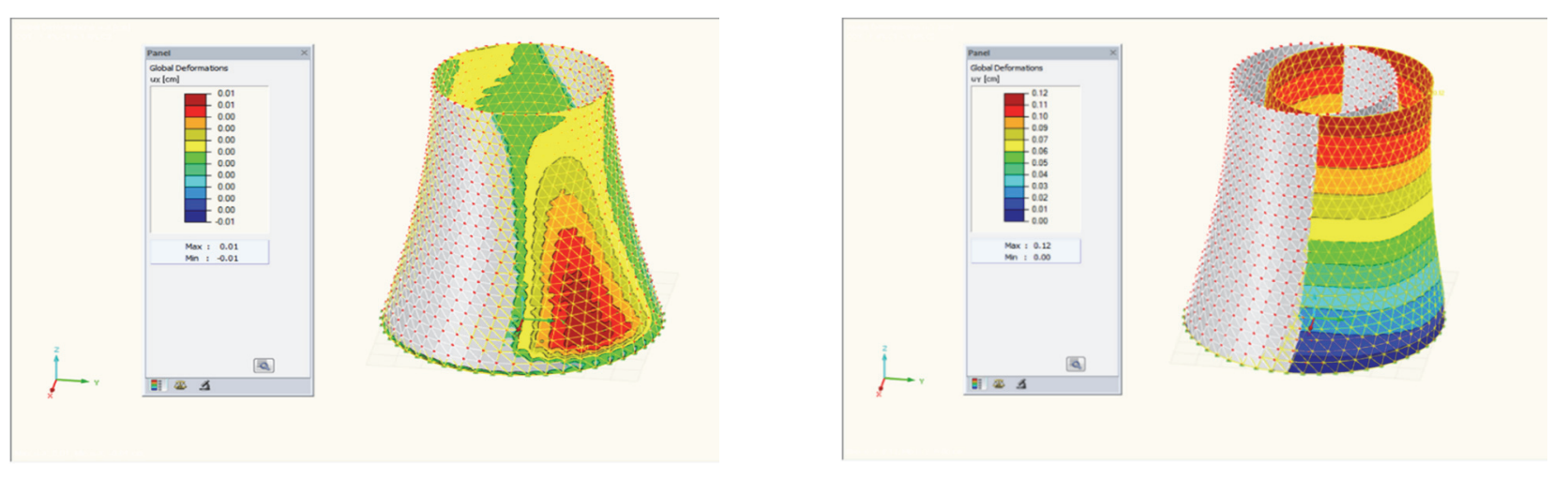

$$
U x=0.01 \mathrm{~cm}
$$

$U y=0.12 \mathrm{~cm}$

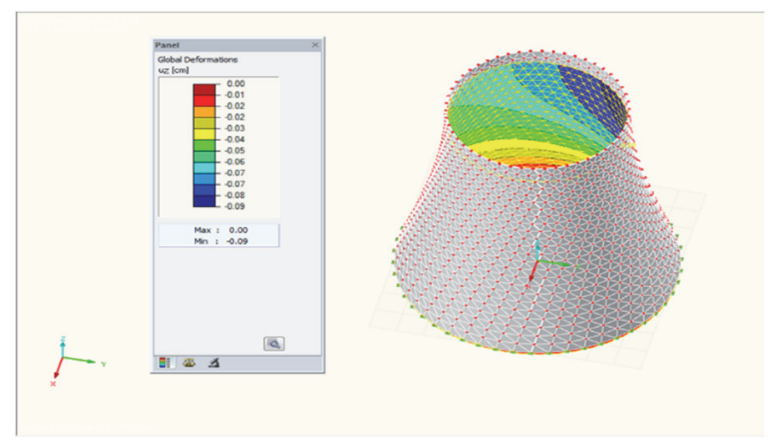

$U z=-0.09 \mathrm{~cm}$

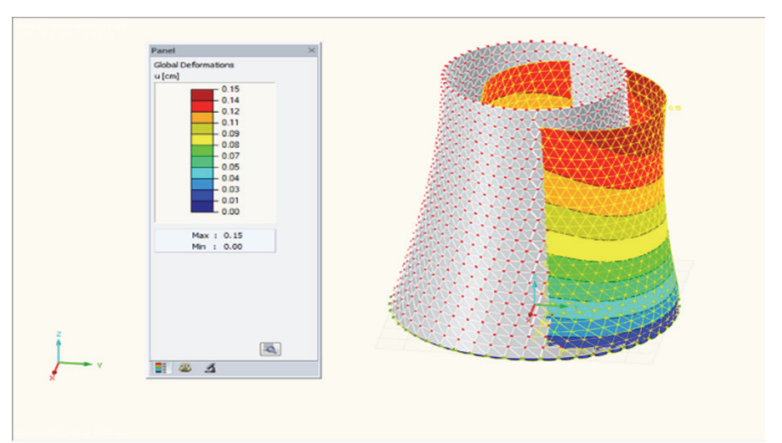

Overall displacement $U=0.15 \mathrm{~cm}$

Figure 6. Linear analysis

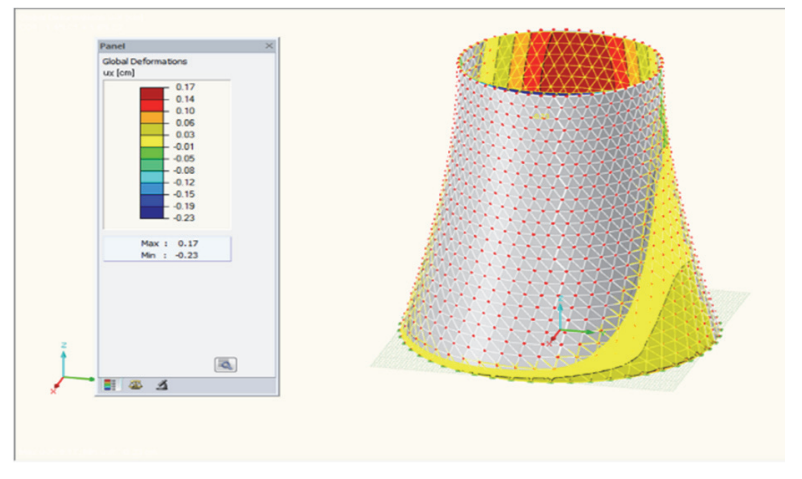

$U x=0.17 \mathrm{~cm}$

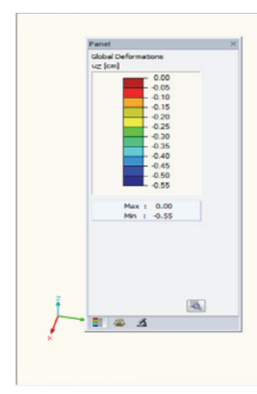

$U z=-0.55 \mathrm{~cm}$

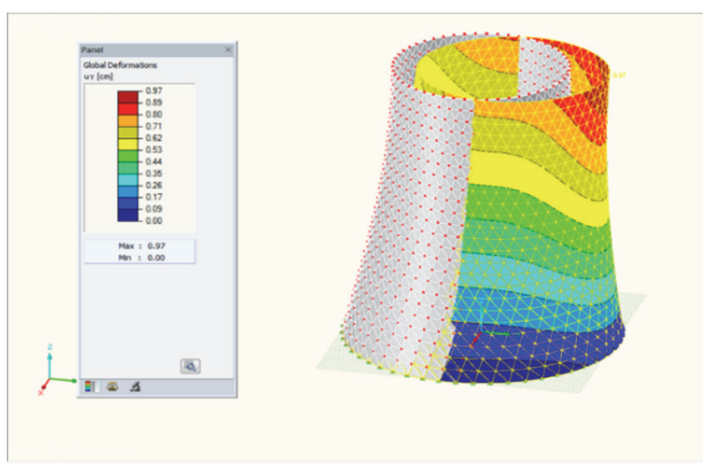

$U y=0.97 \mathrm{~cm}$

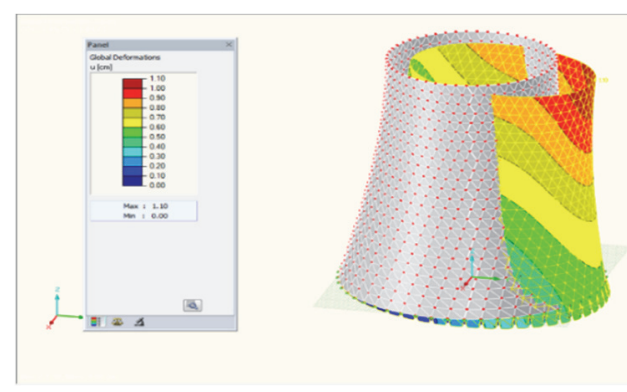

Overall displacement $U=1.1 \mathrm{~cm}$

Figure 7. Nonlinear analysis 
Table

\begin{tabular}{|c|c|c|c|c|c|c|}
\hline Displacements & Mode & \multicolumn{2}{|c|}{ Linear and nonlinear analysis } & Mode & Natural frequency, & Natural period, \\
\hline \multirow{3}{*}{$U x(\max , \min ) \mathrm{cm}$} & 1 & 0.937 & 0.76 & \multirow{3}{*}{1} & \multirow{3}{*}{3.676} & \multirow{3}{*}{0.272} \\
\hline & 2 & 0.98 & 0.64 & & & \\
\hline & 3 & 0.91 & 0.91 & & & \\
\hline \multirow{3}{*}{$U y(\max , \min ) \mathrm{cm}$} & 1 & 0.64 & 0.98 & \multirow{3}{*}{2} & \multirow{3}{*}{3.678} & \multirow{3}{*}{0.272} \\
\hline & 2 & 0.76 & 0.93 & & & \\
\hline & 3 & 0.91 & 0.91 & & & \\
\hline \multirow{3}{*}{$U z(\max , \min ) \mathrm{cm}$} & 1 & 0.068 & 0.068 & \multirow{3}{*}{3} & \multirow{3}{*}{4.118} & \multirow{3}{*}{0.243} \\
\hline & 2 & 0.067 & 0.067 & & & \\
\hline & 3 & 0.11 & 0.11 & & & \\
\hline
\end{tabular}
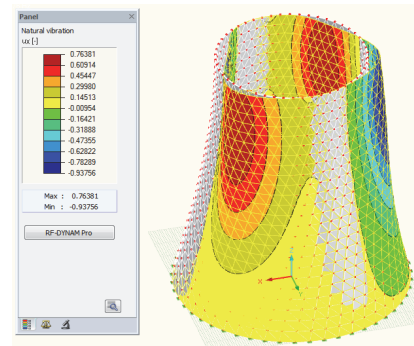

Mode1 Ux displacement

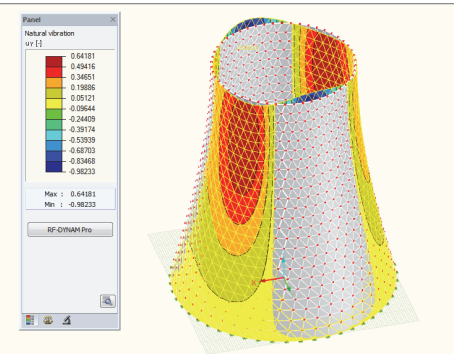

Mode1 Uy displacement
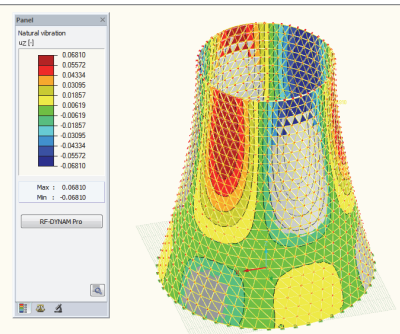

Mode1 Uz displacement

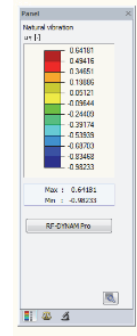

Model 2 Uy displacement
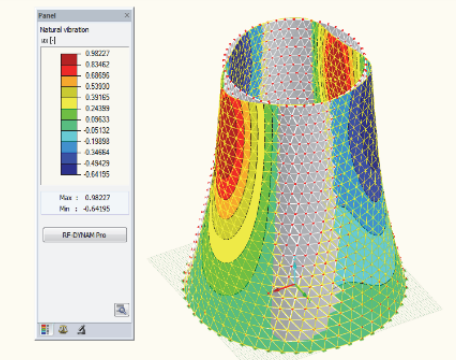

Model 2 Ux displacement

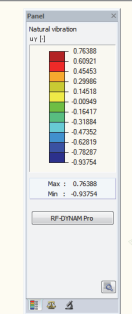

Model 2 Uz displacement
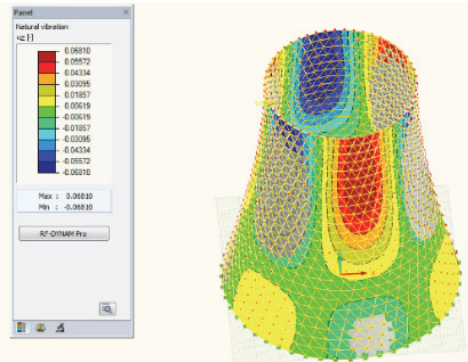

Model 3 Uz displacement
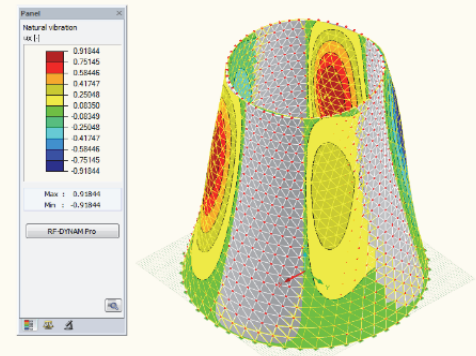

Model 3 Ux displacement

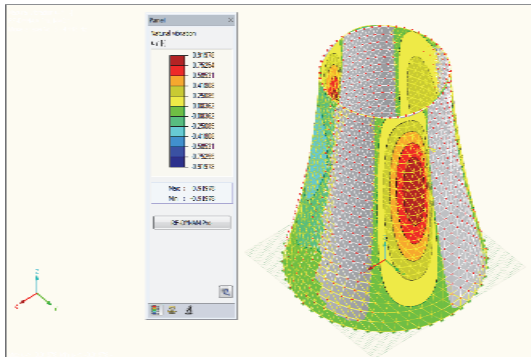

Model 3 Uy displacement

Figure 8. Models of $U x, U y$ and $U z$ displacements

\section{Conclusion}

The linear and the materially nonlinear analyses (MNA) investigations of the stability behavior of thin shells in the form of an hyperboloid of revolution by the software program R-FEM show that for both linear and materially nonlinear analyses:
- the values of displacements under materially nonlinear analysis are bigger than those obtained from linear analysis subject to self-weight and wind load;

- there is a similarity between the results of linear and materially nonlinear analyses for this investigated thin shell subject to free vibration. 


\section{References}

1. Petropavlovskaya I.A. (1988). Giperboloidnye konstrukcii v stroitel'noj mekhanike [Hyperboloid constructions in structural mechanics]. Moscow: Nauka Publ. (In Russ.)

2. Trushin S.I., Petrenko Ph.I. (2017). Vliyanie fizicheskoj nelinejnosti na raschetnye pokazateli ustojchivosti gibkih setchatyh odnopolostnyh giperboloidov vrashcheniya s obrazuyushchimi razlichnyh form [Influence of physical nonlinearity on the calculated indicators of stability of reticulated one-sheet hyperboloid of revolution with different forms of generatrixes]. Structural Mechanics of Engineering Constructions and Buildings, (4), 50-56. doi: 10.22363/1815-5235-2017-4-50-56 (In Russ.)

3. Krivoshapko S.N. (2002). Static, vibration and buckling analysis and applications to one-sheet hyperboloidal shells of revolution. Applied Mechanic Reviews, 55(3), 241-270. doi:10.1115/1.1470479

4. Reddy J.N. (2005). An introduction to nonlinear finite element analysis. New York: Oxford University Press.

5. Trushin S.I., Petrenko Ph.I. (2014). Vliyanie morfologii setchatogo giperboloida na ego napryazhenno-deformirovannoe sostoyanie, ustojchivost' i osnovnye chastoty [The influence of the morphology of reticulated hyperboloid on its stressstrain state, stability and fundamental frequencies]. Structural mechanics and analysis of structures, (4), 59-64. (In Russ.)

6. Trushin S.I., Petrenko Ph.I. (2016). Analysis of the stability of flexible reticulated shells in the form of a hyperboloid of revolution. Scientific Review, (6), 95-99.

7. Krivoshapko S.N., Ivanov V.N. (2015). Encyclopedia of Analytical Surfaces. Switzerland: Springer International Publishing.

НАУЧНАЯ СТАТЬЯ

\title{
Геометрическое моделирование и численный расчет физически нелинейных оболочек в форме однополостного гиперболоида вращения
}

\author{
М. Жиль-улбе ${ }^{1}$ М. Джаззан ${ }^{2}$, Д. Кбейли ${ }^{3}$ \\ Российский университет дружбы народов, Российская Федерация, 117198, Москва, ул. Миклухо-Маклая, 6
}

\author{
Ключевые слова: \\ гиперболоиды вращения; \\ материально нелинейный \\ численный анализ; \\ линейный анализ \\ методом конечных элементов; \\ нелинейный анализ \\ методом конечных элементов; \\ геометрическое моделирование
}

История статьи:

Поступила в редакцию: 12 марта 2019 г.

Доработана: 14 мая 2019 г.

Принята к публикации: 10 июня 2019 г.

\section{Для ичтирования}

Gil-oulbé M., Jazzan M., Qbaily J. Geometric modelling and materially nonlinear numerical analysis of shells in the shape of one-sheet hyperboloid of revolution (Геометрическое моделирование и численный расчет физически нелинейных оболочек в форме однополостного гиперболоида вращения) // Строительная механика инженерных конструкций и сооружений. 2019. Т. 15. № 3. С. 210-218. http://dx.doi.org/10.22363/1815-5235-201915-3-210-218

\begin{abstract}
Аннотация
Цели. Поверхность вращения образуется вращением плоской кривой $z=f(x)$ вокруг оси $O z$, называемой осью вращения. В статьи рассматриваются поверхности в форме гиперболоидов вращения и их классификация. Проведены их геометрическое моделирование, линейное и материальнонелинейное исследования.
\end{abstract}

Memoдb. Срединная поверхность гиперболоидов вращения построена с использованием программы MathCAD. Выполнены линейное и материально нелинейное численные исследования напряженно-деформированного состояния тонких оболочек формы гиперболоида вращения с применением метода конечных элементов в компьютерной программе R-FEM. Исходным материалом являлся бетон с изотопной нелинейной 2D/3D-кривой напряжения - деформации для материально-нелинейного исследования и линейной кривой напряжения - деформации для линейного расчета. Представлено сравнение результатов линейного и нелинейного напряженно-деформированных состояний.

Pезультаты. Перемещения в исследованных оболочках под действием собственного веса и ветровой нагрузки при материально-нелинейном исследовании намного превышают перемещения при линейном расчете. С другой стороны, при воздействии свободной вибрации перемещения при линейном и материально нелинейном расчетах равны. Выводы, сделанные на основе полученных данных, приведены в статье.

\footnotetext{
1 Жиль-улбе Матье, кандидат технических наук, доцент, департамент строительства, Инженерная академия, gil-oulbem@hotmail.com

2 Джаззан Муханнад, магистрант, департамент строительства, Инженерная академия.

${ }^{3}$ Кбейли Дюсаафар, магистрант, департамент строительства, Инженерная академия.
} 


\section{Список литературы}

1. Петропавловская И.А. Гиперболоидные конструкции в строительной механике. М.: Наука, 1988. 230 с.

2. Трушин С.И., Петренко Ф.И. Влияние физической нелинейности на расчетные показатели устойчивости гибких сетчатых однополостных гиперболоидов вращения с образующими различных форм // Строительная механика инженерных конструкций и сооружений. 2017. № 4. C. 50-56. doi: 10.22363/1815-5235-2017-4-50-56

3. Krivoshapko S.N. Static, vibration and buckling analysis and applications to one-sheet hyperboloidal shells of revolution // Applied Mechanic Reviews. 2002. Vol. 55. No. 3. Pp. 241-270. doi: 10.1115/1.1470479
4. Reddy J.N. An introduction to nonlinear finite element analysis. New York: Oxford University Press, 2005. $463 \mathrm{p}$.

5. Трушин С.И., Петренко Ф.И. Влияние морфологии сетчатого гиперболоида на его напряженнодеформированное состояние, устойчивость и основные частоты // Строительная механика и расчет сооружений. 2014. № 4. C. 59-64.

6. Trushin S.I., Petrenko Ph.I. Analysis of the stability of flexible reticulated shells in the form of a hyperboloid of revolution // Scientific Review. 2016. No. 6. Pp. 95-99.

7. Krivoshapko S.N., Ivanov V.N. Encyclopedia of Analytical Surfaces. Switzerland: Springer International Publishing, 2015. 